Ji-Shan He

\title{
Research Efforts and Fruits of Complex Engineering Management
}

Around the Parallel Session of the 2014 International Conference on Engineering Science and Technology and the $8^{\text {th }}$ China Engineering Management Forum in Beijing in June, 2014, the Division of Engineering Management of the Chinese Academy of Engineering initiated the First International Summit Forum on Engineering Science and Technology Development Strategy on the themes "Major and Complex Engineering Management and Engineering Management Body of Knowledge" and the $9^{\text {th }}$ China Engineering Management Forum on the themes "Green Urban Construction and Pollution Prevention/Control", in Guangzhou, in May, 2015.

At the 2014 Beijing Forum, the members of the Organizational Committee of the 2015 Guangzhou Forums began to issue special invitations and deliver informal calls for papers; and in November, 2014, the Organizational Committee delivered formal calls for papers for the 2015 Guangzhou Forums.

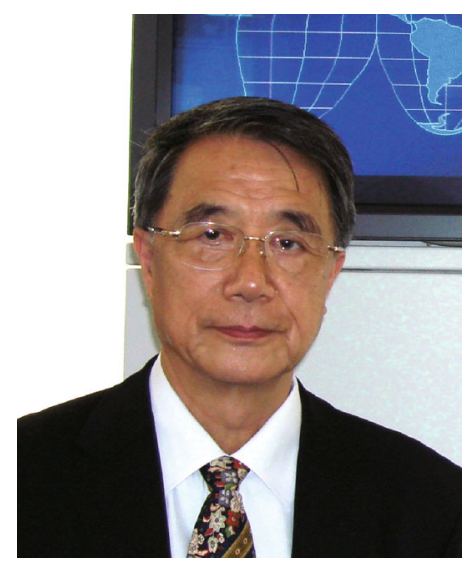

The invitations were accepted, and the calls, informal and formal, were responded to, all very quickly. The papers selected from the 2014 Beijing Forum were still in the editorial process, of which some were published in the $4^{\text {th }}$ issue of 2014 and some were to be published in the 2015 issues, when paper proposals or drafts for the 2015 Guangzhou Forums were forwarded to the editorial office of Frontiers of Engineering Management by the Organizational Committee. This is something signaling not only the success of the 2015 Guangzhou Forums, but also the fruits of the research efforts on complex project management.

The quick accepting of the invitations and responding to the calls show that complex engineering project management has excited common concern from the professional communities in the fields concerning engineering and engineering.

Innovations in complex engineering management are crucial to the success of complex engineering projects, and such innovations are very often the fruits of the common research efforts of the professional communities in a variety of fields of sciences, natural, social and humanistic.

Complex engineering projects, after all, are of vital importance to the world as they can change much of the world and of the life in the world.

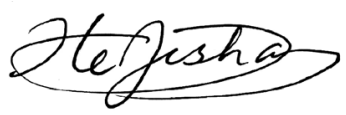

March 1, 2015 